\title{
Monitoring Heterogeneously Catalyzed Hydrogenation Reactions at Elevated Pressures Using In-Line Flow NMR
}

\author{
Koen C. H. Tijssen, ${ }^{\dagger}$ Bram J. A. van Weerdenburg, ${ }^{\dagger}$ Hainan Zhang, ${ }^{\S}$ J. W. G. Janssen, ${ }^{\dagger}$ \\ Martin C. Feiters, ${ }^{\ddagger 0}$ P. Jan M. van Bentum, ${ }^{\dagger}$ and Arno P. M. Kentgens ${ }^{*},^{\dagger}$ \\ ${ }^{\dagger}$ Magnetic Resonance Research Center, Institute for Molecules and Materials and ${ }^{\ddagger}$ Synthetic Organic Chemistry, Institute for \\ Molecules and Materials, Radboud University, Nijmegen, The Netherlands \\ ${ }^{\S}$ Mesoscale Chemical Systems, Mesa+ Institute for Nanotechnology, University of Twente, Enschede, The Netherlands
}

Supporting Information

ABSTRACT: We present a novel setup that can be used for the in-line monitoring of solid-catalyzed gas-liquid reactions. The method combines the high sensitivity and resolution of a stripline NMR detector with a microfluidic network that can withstand elevated pressures. In our setup we dissolve hydrogen gas in the solvent, then flow it with the added substrate through a catalyst cartridge, and finally flow the reaction mixture directly through the stripline NMR detector. The method is quantitative and can be used to determine the solubility of hydrogen gas in liquids; it allows in-line monitoring of hydrogenation reactions and can be used to determine the reaction kinetics of these reactions. In this work, as proof of concept we demonstrate the optimization of the

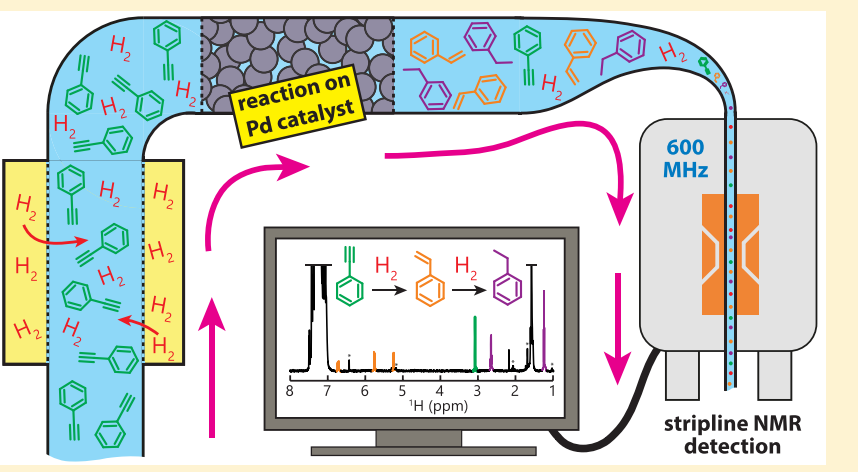
Pd-catalyzed hydrogenation reactions of styrene, phenylacetylene, cyclohexene, and hex-5-en-2-one in a microfluidic context.

Sis ince the transition from alchemy to chemistry as a science, chemists have made use of glass flasks (e.g., Erlenmeyer and round-bottom flasks) or large stainless steel vessels. At the end of the 20th century microreactors were introduced into the field of chemistry. These submillimeter flow reactors provide several advantages over large-volume batch processes performed in flasks or reaction vessels, namely, faster mixing, better control over reaction times and temperature (excellent heat exchange), continuous operation, improved safety, the capability to work at high pressures without major modifications to the setup, and finally the possibility to work at higher concentrations. As a result, microreactor synthesis can be more sustainable and economic. ${ }^{1}$

The change from a batch process to a continuous process requires a continuous monitoring of the reaction process by inand online analysis. The difference between the two is that for online analysis a fraction of the reaction mixture is separated from the main reaction volume and directed through a detector before it is reunited with the main reaction volume, whereas in in-line analysis the detection is done directly on the main reaction volume. In- or online analysis of a reaction mixture can provide valuable information about reactive intermediates and reaction kinetics, and it makes on-the-fly optimization of the reaction possible. Therefore, in- or online versions of the most-used spectroscopic techniques, i.e., UV, IR, Raman, and fluorescence, were developed. ${ }^{2}$ One of the most informationrich techniques in chemical analysis is NMR; it not only provides structural information but also gives quantitative results. Both online $\mathrm{e}^{3-8}$ and in-line NMR techniques ${ }^{8-15}$ exist. Noteworthy are the setups in which benchtop NMR systems are used. ${ }^{16-20}$ Although the sensitivity and chemical shift dispersion of these systems are smaller compared to the highfield systems, the costs are more than an order of magnitude lower and no cryogenics are needed.

Microfluidic setups work fine as long as all of the reactants remain liquid or dissolved. However, several problems are to be expected if one of the components is a gas. The gas may cause instability in the flow rate, the in-line pressure, and the heat conductivity. In the case of multiple flow routes or a catalyst cartridge it can block certain flow routes or volume sections of the cartridge, thereby decreasing the total reaction volume. NMR-wise the gas not only decreases the signal intensity but is also detrimental for the spectral resolution because of the magnetic susceptibility difference between the gas and the liquid. In this work we circumvent this problem by dissolving the gas into the solvent at elevated pressures (up to 7 bar). Standard NMR tubes are not strong enough to safely handle these pressures. However, fused silica capillaries as used in the present study can withstand pressures well over 100 bar, as demonstrated by van Meerten et al. ${ }^{21}$

Performing NMR in-flow in a capillary requires a special setup. The NMR coil has to be adapted so that its dimensions

Received: February 18, 2019

Accepted: September 11, 2019

Published: September 11, 2019 
match those of the capillary in order to obtain a maximum signal-to-noise ratio. Many microcoils have been developed for this purpose. Van Bentum et al. $^{22,23}$ introduced the stripline geometry in NMR as a new radiofrequency (RF) detector that can readily be scaled in size to match small volume samples. Its sensitivity and particularly resolution are better than most other microcoils, and it was shown that stripline NMR can easily be combined with microfluidics to monitor chemical reactions in flow. ${ }^{12,13,24}$

Here we demonstrate the in-line monitoring of the hydrogenation of styrene (Scheme 1) and other substrates

Scheme 1. Hydrogenation Reaction of Styrene

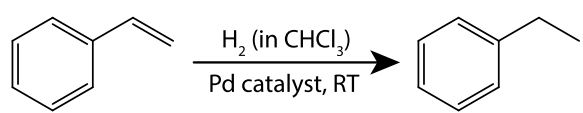

using stripline NMR. The hydrogen gas is dissolved in a substrate solution at elevated pressures with a tube-in-tube system, ${ }^{25,26}$ which consists of a hydrogen-permeable tube inserted in an impermeable tube so that gas in the outer tube can diffuse into the liquid inside the inner tube. The hydrogenrich mixture is led through a cartridge filled with polyureasupported Pd catalyst particles, resulting in a heterogeneously catalyzed hydrogenation reaction. The reactions are performed at room temperature, and the product mixture is directly monitored by in-line stripline NMR (Figure 1).

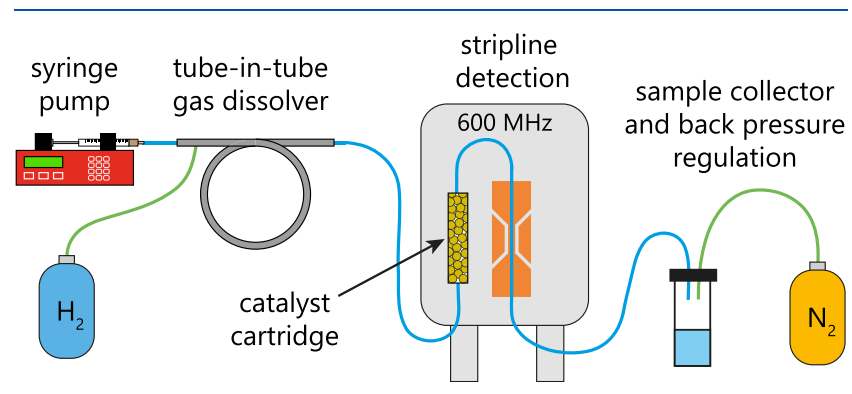

Figure 1. Schematic drawing of the stripline NMR reaction monitoring setup for heterogeneously catalyzed hydrogenation reactions.

Buser and McFarland ${ }^{27}$ already demonstrated online NMR monitoring of hydrogenation reactions at elevated pressures. The main differences between their work and our work is that they created an online setup with a large $(100 \mathrm{~mL})$ reaction vessel and a custom-made NMR flow tube for detection, whereas we created an in-line setup in which the reaction is performed in a small $(208 \mu \mathrm{L})$ stainless steel cartridge filled with catalyst and a stripline NMR probe, dedicated for NMR experiments on small-volume samples in capillaries.

\section{EXPERIMENTAL SECTION}

In-Flow Hydrogenation and Stripline NMR Monitoring Setup. A substrate solution, contained in a $5 \mathrm{~mL}$ gastight syringe (ILS, 2607044), is pumped with a syringe pump (New Era, NE-1000) through a $50 \mathrm{~cm}$ polytetrafluoroethylene (PTFE) tubing $(250 \mu \mathrm{m}$ i.d., $1.59 \mathrm{~mm}$ o.d.) connected via a PEEK luer lock connector (IDEX Health \& Science, P-659) from the syringe to a gas module (Future Chemistry, B-480). This gas module contains a tube-in-tube gas dissolver, which is $50 \mathrm{~cm}$ long and consists of an impermeable fluorinated ethylene-propylene (FEP) outer tubing ( $1.57 \mathrm{~mm}$ i.d., 3.2 $\mathrm{mm}$ o.d.) and a gas-permeable inner tubing (Teflon Amorphous Fluoropolymer AF-2400, $0.61 \mathrm{~mm}$ i.d., $0.81 \mathrm{~mm}$ o.d.). Hydrogen gas is stored in a pressurized cylinder, which is connected to the gas module with FEP tubing. The outlet of the gas module, $250 \mathrm{~cm}$ PTFE tubing $(250 \mu \mathrm{m}$ i.d., $1.59 \mathrm{~mm}$ o.d.), transports the hydrogen-saturated solution to the catalyst cartridge, a $20 \mathrm{~cm}$ long stainless steel tube (IDEX Health \& Science, U-147, $1.15 \mathrm{~mm}$ i.d., $1.59 \mathrm{~mm}$ o.d.) that is completely filled with catalyst particles $(113 \mathrm{mg})$ and closed on both sides with in-line PEEK filters (IDEX Health \& Science, A-430). The other side of the catalyst cartridge is connected to a 140 $\mathrm{cm}$ long fused silica capillary (Polymicro Technologies, 250 $\mu \mathrm{m}$ i.d., $360 \mu \mathrm{m}$ o.d.) that is inserted in the stripline NMR probe and exits the bottom of the probe in a pressurized reservoir. The distance between the catalyst cartridge and the detection point of the stripline probe is $50 \mathrm{~cm}$ (volume $25 \mu \mathrm{L}$ ). The catalyst cartridge is attached to the NMR probe and is placed inside the bore of the NMR magnet; thus, reaction and detection both take place inside the magnet. In principle, the cartridge can also be located outside the magnet, further away from the detection point. However, because it has a relatively large volume compared to a piece of tubing of similar length, we can increase the build-up time of the magnetization without increasing the total length of the fluidic network by placing the cartridge in the center of the magnet.

The final product solution is collected in a reservoir that is pressurized with nitrogen gas. This is done to keep the entire flow system pressurized and to prevent the formation of gas bubbles before the reaction or the detection of the reaction mixture. The same can in principle be done by a back-pressure regulator; however, we found this solution to be more stable. The nitrogen pressure is accurately regulated by a pressurebased flow controller (Fluigent, MFCS). All reactions were performed at room temperature.

Chemicals. Pd microencapsulated in polyurea (Pd Encat 30, $0.4 \mathrm{mmol} / \mathrm{g}$ Pd loading, Sigma-Aldrich) was used as hydrogenation catalyst. Chloroform was obtained from Fisher Scientific. Cyclohexene and phenylacetylene were obtained from Alfa Aesar. Styrene and hex-5-en-2-one from SigmaAldrich and hydrogen gas from Linde Gas. All chemicals were used as received and none of the solvents were degassed.

NMR Experiments and Data Treatment. All NMR experiments in this work are single-pulse excitation ${ }^{1} \mathrm{H}$ NMR measurements performed at $600 \mathrm{MHz}$ using a stripline NMR probe on a $14.1 \mathrm{~T}$ (Oxford 600/89 magnet) Varian NMR system (VNMRS), operating under the VNMRJ software. The stripline NMR probe was designed and produced in house and contains a stripline chip with a constriction (the detection area) that is $9.0 \mathrm{~mm}$ long and $400 \mu \mathrm{m}$ wide. Technical fabrication details of the stripline chip can be found in the work of Oosthoek-De Vries et al. ${ }^{24}$

In the pressure-dependent (Figure 2) and flow ratedependent (Figure S3) hydrogen concentration measurements, a ${ }^{1} \mathrm{H}$ NMR spectrum was acquired every $2 \mathrm{~s}$ at a flow rate of 80 $\mu \mathrm{L} / \mathrm{min}$ or $5 \mathrm{~s}$ for the measurements performed at flow rates of $60 \mu \mathrm{L} / \mathrm{min}$ or less. The flow was allowed to stabilize until all of the peaks in the NMR spectrum reached a constant value. This usually took 10-30 min depending on the flow rate.

For each set of conditions, $160-800$ scans were averaged to improve the signal-to-noise ratio. The spectral width was 10 $\mathrm{kHz}$, and the excitation pulse was between 1.5 and $2.5 \mu \mathrm{s}$ (100-160 kHz rf field strength). Processing of all NMR 


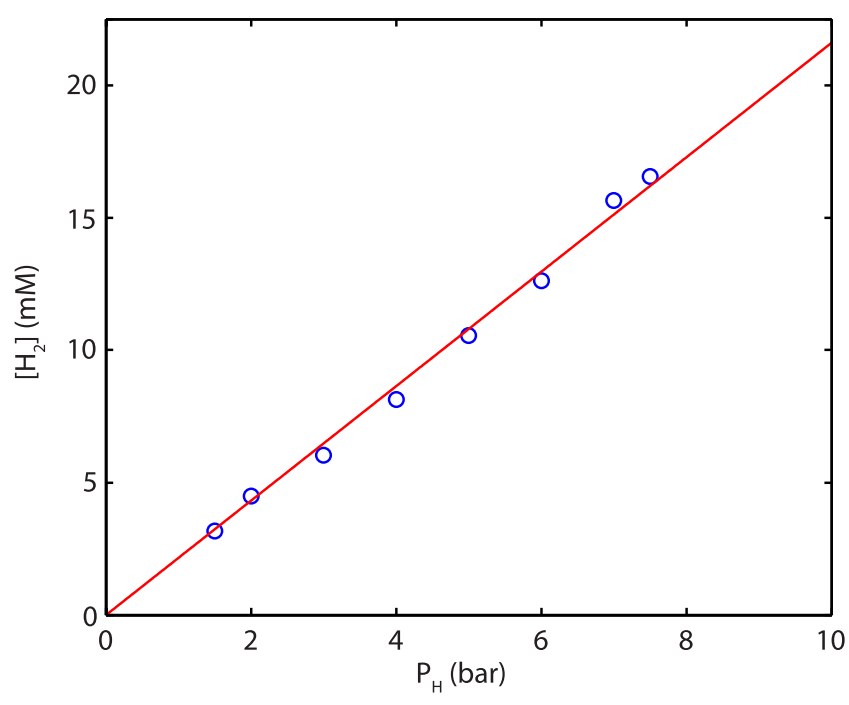

Figure 2. Solubility of hydrogen gas in chloroform as a function of hydrogen gas pressure $\left(P_{\mathrm{H}}\right)$. Flow rate chloroform $=80 \mu \mathrm{L} / \mathrm{min}$.

experiments was done using the MATLAB-based processing package matNMR. ${ }^{28}$

On the basis of an estimation of the errors in the various parts of the experiments (Supporting Information), the accumulated error in the system should be limited to the percent range, thus allowing reliable determination of the kinetic parameters.

For the flow-conversion measurements of the four substrates the NMR spectra were acquired in blocks of 32 scans. Later, during processing, the signals were integrated and plotted to determine when the system was sufficiently stabilized (Figure S1). The spectra acquired after that point were averaged to obtain the conversion percentages. The hydrogen pressure was 7 bar in all cases, whereas the nitrogen back-pressure was set to 5.5 bar. All measurements were performed at room temperature. The recycle delay was adjusted to the flow rate and chosen such that the entire detection volume was refreshed with new sample before each scan. To ensure quantitative data, one should wait for the magnetization to completely build up (3-5 times $\left.T_{1}\right)$. Typical $T_{1}$ relaxation values for the substrates used are 4-5 s. For $\mathrm{H}_{2}$ gas dissolved in chloroform we found a shorter $T_{1}$ relaxation time of $1.1 \mathrm{~s}$. The polarization build-up time is the duration that the reaction mixture spends in the high magnetic field before detection; therefore, it is inversely proportional to the flow rate. In our system the catalyst cartridge is placed near the center of the magnet, and thus, the build-up time is equal to the reaction time in the catalyst cartridge (Figure 3c) plus the time needed to transfer the mixture from the cartridge to the stripline detector. At the highest flow rate used in this work $(300 \mu \mathrm{L} / \mathrm{min})$ these times are 15 and $5 \mathrm{~s}$, respectively, i.e., no additional relaxation delays are needed to warrant quantitative evaluation of the spectra.

\section{RESULTS}

Hydrogen Solubility. The setup was first used to determine the concentration of the dissolved hydrogen gas. There are several methods to measure the gas concentration, or solubility, in a liquid. However, most of them are indirect and measure a change in volume. With NMR the $\mathrm{H}_{2}$ gas can be observed directly and in situ. ${ }^{27,30,31}$ (Note that the peak area of the hydrogen gas corresponds to the hydrogen concentration
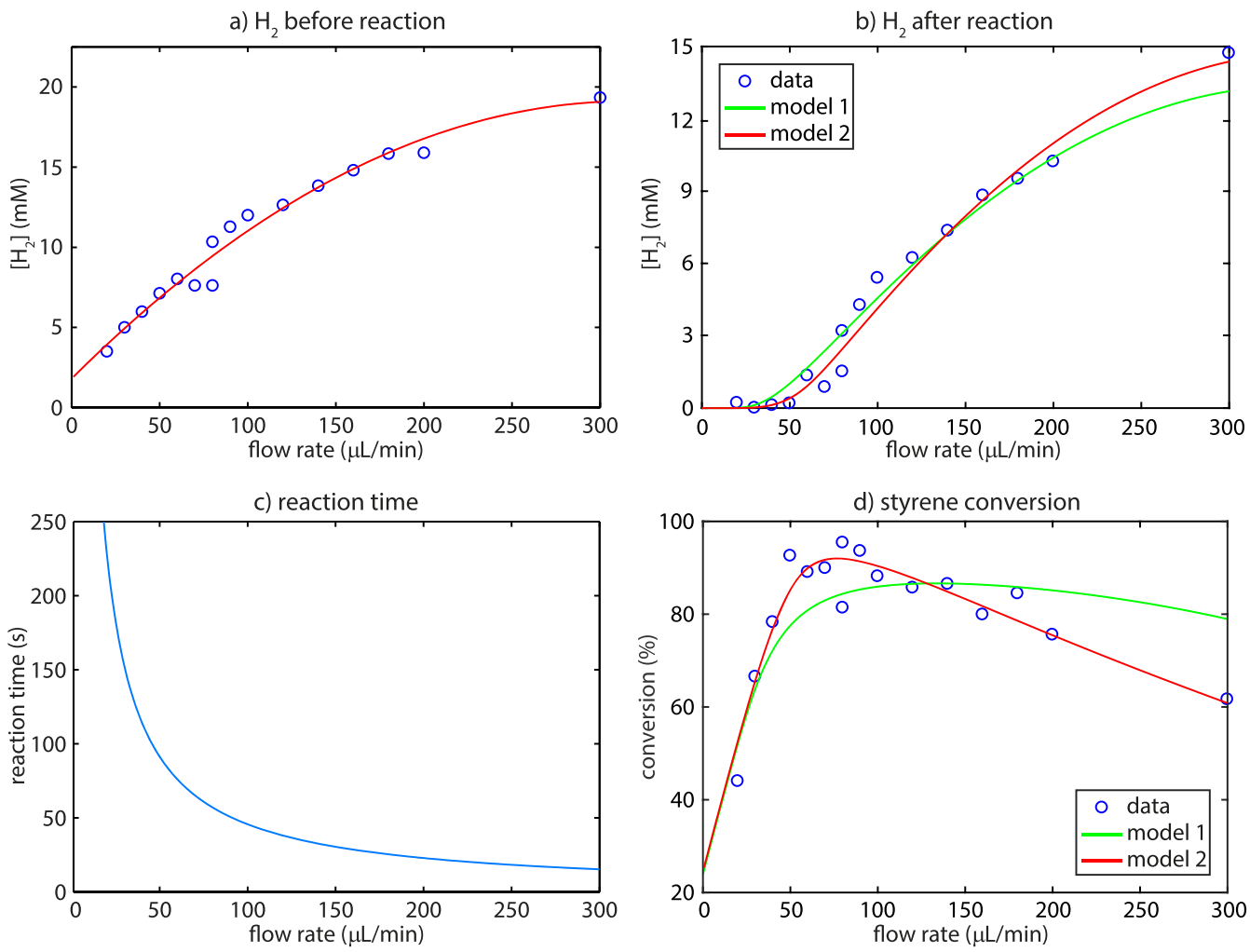

Figure 3. Hydrogenation of styrene: (a) concentration of hydrogen before the reaction and (b) after the reaction. (c) Calculated reaction times. (d) Styrene conversion including the fitted trends based on two models (see text). 

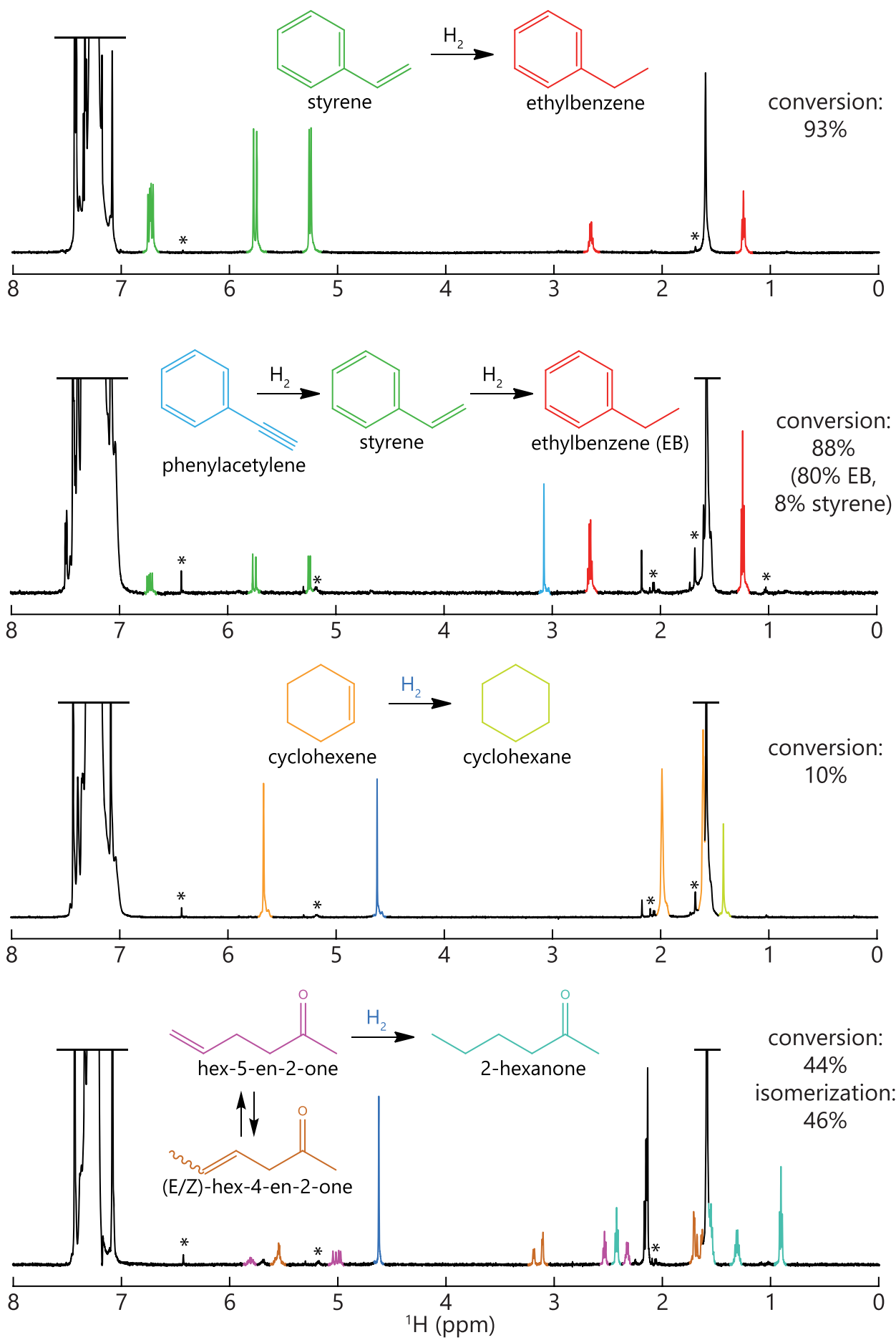

Figure 4. NMR spectra of the reaction mixture of the hydrogenation of styrene (544 scans), phenylacetylene (1920 scans), cyclohexene ( 2560 scans), and hex-5-en-2-one (2080 scans). Asterisks mark impurities in the solvent $\left(\mathrm{CHCl}_{3}, 7.26 \mathrm{ppm}\right)$. Peak at $1.6 \mathrm{ppm}$ is water. Conversion percentages are the maximum conversions and do not necessarily match with the spectra. For all spectra and conversion numbers the initial substrate concentration is $10 \mathrm{mM}$, except for the styrene spectrum, which was recorded for a concentration of $100 \mathrm{mM}$.

in the same way as for all other compounds, despite the fact that the spins are identical and therefore occur in the NMR visible triplet and the NMR invisible singlet state. As is clearly explained by Canet et al., ${ }^{29}$ at equilibrium ortho/para hydrogen ratios the integrated intensity of an $A_{2}$ spin system equals that of an $A X$ system.)

The hydrogen solubility in chloroform was studied at different gas pressures (Figure 2), while the chloroform flow rate was kept constant at $80 \mu \mathrm{L} / \mathrm{min}$. We found a linear dependence of the solubility on the gas pressure, in accordance with Henry's law, and obtained a hydrogen solubility of $2.17 \pm$ $0.08 \mathrm{mM} / \mathrm{bar}$ at room temperature $\left(20^{\circ} \mathrm{C}\right)$, which is slightly lower than the literature values: $2.48^{32}$ and $2.61 \mathrm{mM} /$ bar. $^{33}$

Next we decided to take a closer look at the effect of the flow rate. Because the volumes of both the tube-in-tube gas dissolver and the catalyst cartridge are fixed, a change in flow 
rate will affect the residence time in both compartments. First, we analyzed the performance of the tube-in-tube gas dissolver. Our hypothesis was that at low flow rates the residence time will be long enough to reach maximum hydrogen solubility. At higher flow rates the residence time will become shorter and the concentration of dissolved gas could go down, as reported by Yang and Jensen. ${ }^{34}$ However, we observe a different trend; the concentration of hydrogen dissolved in chloroform drops at lower flow rates, whereas it keeps increasing (nonlinearly) with increasing flow rate up to $200 \mu \mathrm{L} / \mathrm{min}$ (Figure S3). As discussed in section S2 of the Supporting Information, we ruled out a number of explanations for this peculiar behavior. The possibility of gas leaks was excluded, and we deem an explanation based on local turbulences very unlikely. Furthermore, we optically inspected the behavior of the tube-in-tube design under different differential pressures to check whether the inner tube could (partly) collapse. A logical explanation would be that the back pressure in the system rises significantly to pressures above the set hydrogen gas pressure. This would then increase the hydrogen solubility because of the increase in overall pressure. Such large pressure increases are not expected, however, under the flow rates used in this study. The calculated back pressure based on the Poiseuille formula for frictional pressure drop for our system amounts to a maximum pressure drop of approximately 1 bar at a flow rate of approximately $200 \mu \mathrm{L} / \mathrm{min}$. Moreover, under laminar flow one would expect a linear increase in pressure with flow rate and therefore also an linear increase in solubility, which is not what we observe. Nevertheless, we hypothesize that the internal liquid pressure plays a role. As the flow rate is increased a larger pressure drop over the entire length of the microfluidic system is expected. Thus, the syringe pumps will increase the liquid pressure to reach the flow rate to which they are set. This increase in pressure on the liquid should then result in an increased uptake of hydrogen gas and thus a higher hydrogen solubility. Clearly, the observed solubility behavior calls for a more in-depth study of hydrogen concentrations as a function of flow rate, hydrogen pressure, and tube-in-tube design parameters. It should be noted that in a recent paper by Utz and co-workers, ${ }^{35}$ based on a different design, deviations between the simulated concentration profiles and the experimentally observed ones were reported. These observations show that in situ calibration of the hydrogen concentration is of great importance and that NMR is a convenient tool to do so.

Hydrogenation Reactions. We investigated the hydrogenation of four substrates: styrene, cyclohexene, phenylacetylene, and hex-5-en-2-one. For all four substrates an initial concentration of $10 \mathrm{mM}$ was chosen. At low flow rates there is not enough hydrogen dissolved for full conversion of the substrates, whereas at higher flow rates an excess of hydrogen is present. However, at higher flow rates the residence time of the substrate and hydrogen in the catalyst cartridge is decreasing. We thus observe an optimum flow rate for each substrate.

Styrene. The hydrogenation of styrene into ethylbenzene is a fast and well-studied reaction. ${ }^{36,37}$ In our setup it takes place inside the catalyst cartridge. Once the reaction mixture leaves this cartridge the reaction stops and the mixture of ethylbenzene, unreacted styrene, and hydrogen is transported into the NMR probe, where we can detect all three compounds (Figure 4). From the observed ethylbenzene and leftover hydrogen, the initial hydrogen concentration was calculated
(Figure 3a). This concentration profile was fitted with a polynomial (cubic function), which was subsequently used for fitting of the conversion profiles. The initial hydrogen concentration profile is similar in shape to the concentration profile in Figure S3; however, the concentrations are slightly lower. The reason for this is unknown, but small changes in the hydrogen pressure, back pressure, and temperature as well as small errors in the integration of the NMR signals may contribute to this difference. The plot of the hydrogen concentration after the reaction (Figure $3 \mathrm{~b}$ ) indeed shows that there is no more hydrogen left after the reaction at low flow rates and that there is an excess at higher flow rates. The reaction time is equal to the residence time of the reaction mixture in the catalyst cartridge, which can be calculated as a function of the flow rate. For this we need to know the packing density of the cartridge. Since the catalyst particles used are polydisperse spheres (150-250 $\mu \mathrm{m}$ diameter) and the theoretical maximum packing of polydisperse spheres does not deviate much $\left(0-4 \%\right.$ for the Pd particle size range $\left.{ }^{38}\right)$ from monodisperse spheres, we assumed the packing of the catalyst cartridge to be close to the maximum random close packing of monodisperse spheres, ${ }^{39}$ thus occupying $63 \%$ of the $208 \mu \mathrm{L}$ cartridge. The calculated reaction time as a function of the flow rate is given in Figure 3c. Even though the reaction times are long at low flow rates, the conversion will be low because there is not enough hydrogen present, whereas at very high flow rates there is an excess of hydrogen but also a very short reaction time, resulting again in low conversions, and this is exactly what we see if we calculate the conversion from the ethylbenzene concentration (Figure 3d). A flow rate between 50 and $90 \mu \mathrm{L} / \mathrm{min}$ gives an optimal conversion of $90-95 \%$.

In principle, it should be possible to extract the rate constant from this conversion data. Thus, the data was fitted based on a simple second-order reaction (Scheme 2, model 1); however,

\section{Scheme 2. Reaction Models for the Hydrogenation} Reactions

$$
\begin{array}{ll}
\text { Model 1: } & \mathrm{H}_{2}+\text { substrate } \stackrel{\mathrm{kd}}{\longrightarrow} \text { product } \\
\text { Model 2: } & \mathrm{H}_{2}+2 \mathrm{Pd} \stackrel{\mathrm{k}_{1}}{\longrightarrow} 2 \mathrm{Pd}-\mathrm{H} \\
& 2 \mathrm{Pd}-\mathrm{H}+\text { substrate } \stackrel{\mathrm{k}_{2}}{\longrightarrow} \text { product }+2 \mathrm{Pd}
\end{array}
$$

this fit clearly does not match the data well (Figure 3d, model 1). The fit gives a too low maximum conversion and overestimates the conversion at high flow rates. Therefore, we expanded our reaction scheme by explicitly including the function of the Pd catalyst (Scheme 2, model 2). The palladium catalyst first splits the molecular hydrogen and stores it; then in a second step the palladium-bound atomic hydrogen reacts with the substrate to form the hydrogenated product. Now, because the reaction is performed in flow and with an excess of hydrogen (at higher flow rates), it means that the amount of bound hydrogen $(\mathrm{Pd}-\mathrm{H})$ can build up and is not necessarily zero at the start of the reaction, as it would be in a batch reaction.

The amount of palladium in the cartridge was $45.2 \mathrm{mmol}$ (encapsulated in polyurea spheres with a 150-250 $\mu \mathrm{m}$ diameter). We assumed that $100 \%$ of the $\mathrm{Pd}$ is available for the reaction, which gives a $\mathrm{Pd}$ concentration of $0.217 \mathrm{M}$. 
Fitting based on this second model matches the conversion data well (Figure 3d). However, the accuracy of the fitted rate constants $\left(k_{1}=0.16 \pm 0.03 \mathrm{~L} \cdot \mathrm{mol}^{-1} \cdot \mathrm{s}^{-1}\right.$ and $k_{2}=0.59 \pm 0.15$ $\left.\mathrm{L} \cdot \mathrm{mol}^{-1} \cdot \mathrm{s}^{-1}\right)$ is limited, as the scatter in the conversion data is substantial and the number of points is rather low. Nevertheless, the fit does give a reasonable estimate of the size of the rate constants. For more quantitative numbers more data points have to be acquired and other parameters can be varied, for instance, the substrate concentration or the volume or loading of the catalyst cartridge (Figure S5).

The conversion of styrene into ethylbenzene peaked at a flow rate of $70 \mu \mathrm{L} / \mathrm{min}$, giving a conversion of $93 \%$. For the other substrates similar flow-conversion data were gathered (Figures S6-S8). In all cases a substrate concentration of 10 $\mathrm{mM}$ was used.

Phenylacetylene. Phenylacetylene can react twice with hydrogen. In the first step styrene is formed, which reacts into ethylbenzene. We see a maximum styrene concentration at a flow rate of $40 \mu \mathrm{L} / \mathrm{min}$ (Figure S6) when there is not enough $\mathrm{H}_{2}$ dissolved to let the phenylacetylene fully react into ethylbenze. At that flow rate $15 \%$ of the phenylacetylene is reacted into styrene. At higher flow rates the final styrene concentration slightly decreases, whereas the ethylbenzene concentration keeps increasing up to a flow rate of $200 \mu \mathrm{L} /$ min. At that flow rate $88 \%$ of the substrate has been converted into ethylbenzene ( $80 \%)$ and styrene $(8 \%)$. For this system the hydrogen concentration is limiting the conversion; only at the highest flow rates an initial hydrogen concentration of $20 \mathrm{mM}$, which is the minimum for a full conversion into ethylbenzene, is reached.

Cyclohexene. The hydrogenation of cyclohexene exhibits a conversion profile similar to that of styrene (Figure S7) with a maximum conversion of only $10 \%$ at a flow rate of roughly 60 $\mu \mathrm{L} / \mathrm{min}$. Apparently the rate constant for this hydrogenation reaction is too low to reach a higher conversion in the time the reaction mixture flows through the cartridge. Thus, either a longer cartridge or elevated temperatures are needed to obtain a higher conversion.

Hex-5-en-2-one. The reaction of hex-5-en-2-one with $\mathrm{H}_{2}$ in the presence of the $\mathrm{Pd}$ catalyst is a special case, because not only does the substrate convert into 2 -hexanone via hydrogenation but also it isomerizes into both $(E)$-hex-4-en-2-one and $(Z)$-hex-4-en-2-one (Figure 4$)$. Both the Pd catalyst and the $\mathrm{H}_{2}$ have to be present for this isomerization to occur. Unfortunately, the resonances of the methyl protons (1.6-1.7 ppm) and the protons attached to the double bond (5.5-5.6 ppm) overlap in the spectrum and cannot be used to distinguish the two hex-4-en-2-one isomers. However, the peaks of the protons on the $\mathrm{C} 3$ carbon (doublets at 3.11 and $3.19 \mathrm{ppm}$ ) are well separated and can be integrated. On the basis of the different $J$ couplings we assume that the doublet at $3.11 \mathrm{ppm}(5.6 \mathrm{~Hz})$ is the $E$ isomer and the doublet at $3.19 \mathrm{ppm}$ $(7.3 \mathrm{~Hz})$ is the $Z$ isomer. The isomer ratio is roughly $2: 1$ ( $E$ : $Z$ ), and a larger percentage of hex-5-en-2-one isomerizes at lower flow rates $(52 \%$ at $40 \mu \mathrm{L} / \mathrm{min}$ compared to $40 \%$ at 150 $\mu \mathrm{L} / \mathrm{min}$, Figure S8) when the reaction time is long and the hydrogen concentration is low. The hydrogenation conversion is around $40 \%$ at all tested flow rates. The maximum conversion into 2-hexanone that we measured is $44 \%$ at 80 $\mu \mathrm{L} / \mathrm{min}$. At that flow rate $46 \%$ of the starting material (hex-5en-2-one) is converted to and detected as one of the two hex4-en-2-one isomers. The hex-4-en-2-one isomers can also be hydrogenated, and it is likely that a fraction of the detected 2- hexanone originates from hydrogenated hex-4-en-2-one. More in-depth characterization is needed to determine the rate constants for the hydrogenation of both hex-5-en-2-one and hex-4-en-2-one.

\section{- CONCLUSIONS AND OUTLOOK}

We created a microfluidic flow setup in which solid-catalyzed gas-liquid reactions can take place, allowing direct monitoring of the reaction product by in-line stripline NMR detection. We have shown that this setup can be used to study heterogeneously catalyzed hydrogenation reactions. Dissolving the gas in the solvent at elevated pressures makes the microfluidic system more stable and prevents spectral distortions that can occur in a plug-flow system, in which gas and liquid plugs are alternated. Some instability was observed during the initial 10-30 min after changing the flow rate. We expect that this stabilization period can be shortened in the future by integrating a pump, tube-in-tube gas dissolver, and sample collector in the NMR probe and thereby reducing the length of the tubing and capillaries.

The high sensitivity of the stripline in combination with the microfluidic capillary allows one to perform NMR measurements at elevated pressures. In this work we used pressures up to $8 \mathrm{bar}$; however, the capillary can withstand pressures well over 100 bar. Besides higher pressures, the size of the cartridge can be adjusted to change the reaction time or the cartridge can be swapped for other microreactors, for instance, microchannel reactors in which the catalyst is immobilized to the channel wall.

Our study underlines the importance of in-line monitoring of the hydrogen concentration. In flow systems it cannot be taken for granted that the dissolved gas concentration is maximized and independent of the solvent flow rate. Simulations based on a multitude of parameters may predict concentrations for simple idealized flow systems; ${ }^{34}$ however, this might turn out quite different in more complicated flow systems as presented here and elsewhere. ${ }^{35}$ Without in situ determination of the hydrogen concentration, any attempt to determine a reaction mechanism, or even reaction yield, is flawed. With our stripline NMR setup the dissolved hydrogen gas can be calibrated with ease.

One drawback of our method is that the substrate concentration is limited by the solubility of hydrogen in the solvent used. A solution for this might be to "charge" the catalyst with plugs of hydrogen gas. When a hydrogen gas plug enters the cartridge the catalyst adsorbs the hydrogen. Later, when a solution plug flows through the catalyst, the catalyst "discharges" as the adsorbed hydrogen reacts in the hydrogenation of the substrate. In such a plug-flow method, plugs of hydrogen gas and substrate solution are thus alternated to adsorb large quantities of hydrogen and to hydrogenate high substrate concentrations. Such an approach has been described for solid-catalyzed hydrogenation reactions. ${ }^{40,41}$

The method presented here is not limited to hydrogenation reactions, so many more reactions can be monitored using this approach. By placing the cartridge right over the stripline one may even directly observe what happens at the catalyst. By changing the stripline chip for a tapered stripline chip ${ }^{13}$ one can observe concentration profiles over the catalyst cartridge similar to MRI-type experiments. ${ }^{42-44}$ Depending on their lifetime, it may even be possible to observe catalytic species and intermediates directly, because the amount of catalyst is high compared to the amount of substrate which is in the 
cartridge at any point in time. Heterogeneously catalyzed hydrogenation reactions have been studied for many decades, and although there is a general consensus that the HoriutiPolanyi mechanism ${ }^{45,46}$ is the underlying mechanism for the addition of $\mathrm{H}_{2}$ to alkenes and alkynes, there are still many unanswered questions. ${ }^{47}$ What are the effects of olefin decomposition reactions on the reactivity of the catalyst? What determines the selectivity of the reaction? How do different crystal surfaces and nanoparticle sizes affect the hydrogenation process? Using our setup it is possible to study hydrogenation reactions and their catalysts in situ and might therefore provide answers to the questions stated above.

A final opportunity for our setup lies in the combination of our setup with parahydrogen-induced polarization (PHIP), ${ }^{48,49}$ which is a technique that uses the special properties of one of the spin isomers of hydrogen, the so-called parahydrogen, to get a signal enhancement of a factor 100-10 000. This allows one to detect molecules in much lower concentrations. This can benefit the detection of unwanted low-concentration side products or the study of catalytic reaction mechanisms by easier detection of short-lived catalytic species and reaction intermediates. Note that in this case the Pd catalyst needs to be replaced by a catalyst that preserves the spin correlation of the parahydrogen. In the literature there are already multiple examples $^{58-53}$ of studies that successfully use PHIP to investigate hydrogenation mechanisms, kinetics, and the effects of support materials, particle sizes, and different crystal facets, most notably by the group of Koptyug. ${ }^{54-56}$ Recently, it was shown that PHIP hyperpolarization can be achieved in similar continuous flow setups in which hydrogen dissolved in a liquid by diffusion through a membrane. ${ }^{35,57,58}$

\section{ASSOCIATED CONTENT}

\section{S Supporting Information}

The Supporting Information is available free of charge on the ACS Publications website at DOI: 10.1021/acs.analchem.9b00895.

Stabilization; hydrogen concentration as a function of flow rate; reaction constants of styrene hydrogenation; conversion profiles; experimental accuracy (PDF)

\section{AUTHOR INFORMATION}

\section{Corresponding Author}

*E-mail: a.kentgens@nmr.ru.nl.

\section{ORCID}

Martin C. Feiters: 0000-0003-0130-835X

Arno P. M. Kentgens: 0000-0001-5893-4488

\section{Notes}

The authors declare no competing financial interest.

\section{ACKNOWLEDGMENTS}

We thank Renée Ripken and Robin Burgers for their contributions in the early stages of this project, Professor Floris Rutjes (Radboud University Nijmegen) and Professor Han Gardeniers (Twente University) for discussions, and the staff of Future Chemistry for their help with the experimental setup. We also acknowledge the technical support provided by Gerrit Janssen and Ruud Aspers. We thank The Netherlands Organization for Scientific Research (NWO) and the Institute for Molecules and Materials for their support of the NMR facility. We are grateful to the European Union and the provinces of Gelderland and Overijssel for their support of the EFRO (Europees Fonds voor Regionale Ontwikkeling) Ultrasense NMR project.

\section{REFERENCES}

(1) Plutschack, M. B.; Pieber, B.; Gilmore, K.; Seeberger, P. H. Chem. Rev. 2017, 117, 11796-11893.

(2) Yue, J.; Schouten, J. C.; Nijhuis, T. A. Ind. Eng. Chem. Res. 2012, 51, 14583-14609.

(3) Maiwald, M.; Fischer, H. H.; Kim, Y.-K.; Albert, K.; Hasse, H. J. Magn. Reson. 2004, 166, 135-146.

(4) Bernstein, M. A.; Śtefinović, M.; Sleigh, C. J. Magn. Reson. Chem. 2007, 45, 564-571.

(5) Foley, D. A.; Bez, E.; Codina, A.; Colson, K. L.; Fey, M.; Krull, R.; Piroli, D.; Zell, M. T.; Marquez, B. L. Anal. Chem. 2014, 86, 12008-12013.

(6) Hall, A. M. R.; Chouler, J. C.; Codina, A.; Gierth, P. T.; Lowe, J. P.; Hintermair, U. Catal. Sci. Technol. 2016, 6, 8406-8417.

(7) Gomez, M. V.; Rodriguez, A. M.; de la Hoz, A.; JimenezMarquez, F.; Fratila, R. M.; Barneveld, P. A.; Velders, A. H. Anal. Chem. 2015, 87, 10547-10555.

(8) Gomez, M. V.; de la Hoz, A. Beilstein J. Org. Chem. 2017, 13, 285-300.

(9) Khajeh, M.; Bernstein, M. A.; Morris, G. A. Magn. Reson. Chem. 2010, 48, 516-522.

(10) Fyfe, C. A.; Cocivera, M.; Damji, S. W. H. Acc. Chem. Res. 1978, 11, 277-282.

(11) Wensink, H.; Benito-Lopez, F.; Hermes, D. C.; Verboom, W.; Gardeniers, H. J. G. E.; Reinhoudt, D. N.; van den Berg, A. Lab Chip 2005, 5, 280-284.

(12) Bart, J.; Kolkman, A. J.; Oosthoek-de Vries, A. J.; Koch, K.; Nieuwland, P. J.; Janssen, H. J. W. G.; van Bentum, J. P. J. M.; Ampt, K. A. M.; Rutjes, F. P. J. T.; Wijmenga, S. S.; Gardeniers, H. J. G. E.; Kentgens, A. P. M. J. Am. Chem. Soc. 2009, 131, 5014-5015.

(13) Tijssen, K. C. H.; Bart, J.; Tiggelaar, R. M.; Janssen, J. W. G. H.; Kentgens, A. P. M.; van Bentum, P. J. M. J. Magn. Reson. 2016, 263, $136-146$

(14) Gomez, M. V.; Juan, A.; Jiménez-Márquez, F.; de la Hoz, A.; Velders, A. H. Anal. Chem. 2018, 90, 1542-1546.

(15) Oosthoek-de Vries, A. J.; Nieuwland, P. J.; Bart, J.; Koch, K.; Janssen, J. W. G.; van Bentum, P. J. M.; Rutjes, F. P. J. T.; Gardeniers, H. J. G. E.; Kentgens, A. P. M. J. Am. Chem. Soc. 2019, 141, 53695380.

(16) Danieli, E.; Perlo, J.; Duchateau, A. L. L.; Verzijl, G. K. M.; Litvinov, V. M.; Blümich, B.; Casanova, F. ChemPhysChem 2014, 15 3060-3066.

(17) Silva Elipe, M. V.; Milburn, R. R. Magn. Reson. Chem. 2016, 54, 437-443.

(18) Zientek, N.; Laurain, C.; Meyer, K.; Kraume, M.; Guthausen, G.; Maiwald, M. J. Magn. Reson. 2014, 249, 53-62.

(19) Sans, V.; Porwol, L.; Dragone, V.; Cronin, L. Chem. Sci. 2015, $6,1258-1264$

(20) Goldbach, M.; Danieli, E.; Perlo, J.; Kaptein, B.; Litvinov, V. M.; Blümich, B.; Casanova, F.; Duchateau, A. L. Tetrahedron Lett. 2016, 57, 122-125.

(21) van Meerten, S. G. J.; Tayler, M. C. D.; Kentgens, A. P. M.; van Bentum, P. J. M. J. Magn. Reson. 2016, 267, 30-36.

(22) Bentum, P. J. M. v.; Janssen, J. W. G.; Kentgens, A. P. M. Analyst 2004, 129, 793-803.

(23) van Bentum, P.; Janssen, J.; Kentgens, A.; Bart, J.; Gardeniers, J. J. Magn. Reson. 2007, 189, 104-113.

(24) Oosthoek-de Vries, A. J.; Bart, J.; Tiggelaar, R. M.; Janssen, J. W. G.; van Bentum, P. J. M.; Gardeniers, H. J. G. E.; Kentgens, A. P. M. Anal. Chem. 2017, 89, 2296-2303.

(25) Brzozowski, M.; O’Brien, M.; Ley, S. V.; Polyzos, A. Acc. Chem. Res. 2015, 48, 349-362.

(26) O’Brien, M.; Taylor, N.; Polyzos, A.; Baxendale, I. R.; Ley, S. V. Chem. Sci. 2011, 2, 1250-1257. 
(27) Buser, J. Y.; McFarland, A. D. Chem. Commun. 2014, 50, 42344237.

(28) van Beek, J. D. J. Magn. Reson. 2007, 187, 19-26.

(29) Canet, D.; Aroulanda, C.; Mutzenhardt, P.; Aime, S.; Gobetto, R.; Reineri, F. Concepts Magn. Reson., Part A 2006, 28A, 321-330.

(30) Krüger, M. B.; Selle, C.; Heller, D.; Baumann, W. J. Chem. Eng. Data 2012, 57, 1737-1744.

(31) Beach, N. J.; Knapp, S. M. M.; Landis, C. R. Rev. Sci. Instrum. 2015, 86, 104101.

(32) Shirono, K.; Morimatsu, T.; Takemura, F. J. Chem. Eng. Data 2008, 53, 1867-1871.

(33) Young, C. L. Solubility data series; Pergamon Press, 1981; Vols. 5-6 (Hydrogen and Deuterium), p 247.

(34) Yang, L.; Jensen, K. F. Org. Process Res. Dev. 2013, 17, 927933.

(35) Eills, J.; Hale, W.; Sharma, M.; Rossetto, M.; Levitt, M. H.; Utz, M. J. Am. Chem. Soc. 2019, 141, 9955-9963.

(36) Pârvulescu, V. I.; Filoti, G.; Pârvulescu, V.; Grecu, N.; Angelescu, E.; Nicolescu, I. V. J. Mol. Catal. 1994, 89, 267-282.

(37) Betti, C.; Badano, J.; Lederhos, C.; Maccarrone, M.; Carrara, N.; Coloma-Pascual, F.; Quiroga, M.; Vera, C. React. Kinet., Mech. Catal. 2016, 117, 283-306.

(38) Desmond, K. W.; Weeks, E. R. Phys. Rev. E 2014, 90, 022204.

(39) Song, C.; Wang, P.; Makse, H. A. Nature 2008, 453, 629-632.

(40) Yoswathananont, N.; Nitta, K.; Nishiuchi, Y.; Sato, M. Chem. Commun. 2005, 40-42.

(41) Feng, H.; Zhu, X.; Chen, R.; Liao, Q.; Liu, J.; Li, L. Chem. Eng. J. 2016, 306, 1017-1025.

(42) Ulpts, J.; Dreher, W.; Klink, M.; Thöming, J. Appl. Catal., A 2015, 502, 340-349.

(43) Koptyug, I.; Lysova, A.; Kulikov, A.; Kirillov, V.; Parmon, V.; Sagdeev, R. Appl. Catal., A 2004, 267, 143-148.

(44) Bouchard, L.-S.; Burt, S. R.; Anwar, M. S.; Kovtunov, K. V.; Koptyug, I. V.; Pines, A. Science 2008, 319, 442-445.

(45) Horiuti, I.; Polanyi, M. Trans. Faraday Soc. 1934, 30, 11641172.

(46) Mattson, B.; Foster, W.; Greimann, J.; Hoette, T.; Le, N.; Mirich, A.; Wankum, S.; Cabri, A.; Reichenbacher, C.; Schwanke, E. J. Chem. Educ. 2013, 90, 613-619.

(47) Zaera, F. Phys. Chem. Chem. Phys. 2013, 15, 11988-12003.

(48) Green, R. A.; Adams, R. W.; Duckett, S. B.; Mewis, R. E.; Williamson, D. C.; Green, G. G. Prog. Nucl. Magn. Reson. Spectrosc. 2012, 67, 1-48.

(49) Duckett, S. B.; Mewis, R. E. Acc. Chem. Res. 2012, 45, 12471257.

(50) Zhou, R.; Cheng, W.; Neal, L. M.; Zhao, E. W.; Ludden, K.; Hagelin-Weaver, H. E.; Bowers, C. R. Phys. Chem. Chem. Phys. 2015, 17, 26121-26129.

(51) Wang, W.; Xu, J.; Zhao, Y.; Qi, G.; Wang, Q.; Wang, C.; Li, J.; Deng, F. Phys. Chem. Chem. Phys. 2017, 19, 9349-9353.

(52) Hübler, P.; Giernoth, R.; Kümmerle, G.; Bargon, J. J. Am. Chem. Soc. 1999, 121, 5311-5318.

(53) Zhao, E. W.; Zheng, H.; Zhou, R.; Hagelin-Weaver, H. E.; Bowers, C. R. Angew. Chem., Int. Ed. 2015, 54, 14270-14275.

(54) Zhivonitko, V. V.; Kovtunov, K. V.; Beck, I. E.; Ayupov, A. B.; Bukhtiyarov, V. I.; Koptyug, I. V. J. Phys. Chem. C 2011, 115, 1338613391.

(55) Zhivonitko, V. V.; Skovpin, I. V.; Crespo-Quesada, M.; KiwiMinsker, L.; Koptyug, I. V. J. Phys. Chem. C 2016, 120, 4945-4953.

(56) Salnikov, O. G.; Kovtunov, K. V.; Barskiy, D. A.; Khudorozhkov, A. K.; Inozemtseva, E. A.; Prosvirin, I. P.; Bukhtiyarov, V. I.; Koptyug, I. V. ACS Catal. 2014, 4, 2022-2028.

(57) Lehmkuhl, S.; Wiese, M.; Schubert, L.; Held, M.; Küppers, M.; Wessling, M.; Blümich, B. J. Magn. Reson. 2018, 291, 8-13.

(58) Bordonali, L.; Nordin, N.; Fuhrer, E.; MacKinnon, N.; Korvink, J. G. Lab Chip 2019, 19, 503-512. 